\title{
BILATERAL LUXATIO ERECTA, A CASE REPORT
}

\section{ABSTRACT}

Inferior shoulder dislocation (luxactio erecta) is a rare lesion affecting approximately $0.5 \%$ of dislocations of this joint. The vast majority of these cases occur unilaterally. In September 2004, a 43 year old man was brought to the emergency room of the University Hospital of Santa Maria (HUSM) complaining of bilateral shoulder pain and inability to lower the arms, as a result of a fall with the arms abducted, while carrying out work activities. After physical examination and radiological exams, it was found that the patient had a bilateral inferior shoulder dislocation.
He was referred to the surgical ward and after intravenous sedation, both shoulders were reduced by closed reduction using the traction-countertraction maneuver. The patient was discharged the day after the reduction. Both arms were immobilized with a velpeau sling in total adduction and intrarotation, with instructions to maintain immobilization for three weeks. The patient was also advised to receive physiotherapy.

Keywords - Shoulder/radiography; Shoulder Dislocation; Physical Examination

\section{INTRODUCTION}

Inferior shoulder dislocation (luxatio erecta) is a rare lesion that affects around $0.5 \%$ of case of dislocation of this joint. The great majority of these cases occur unilaterally, and the typical manifestation is characterized by abduction of the affected limb, elbow flexion and forearm pronation, generally with the hand supported on the head. It is strongly correlated with neurological, vascular and tendon lesions, and thus early recognition and treatment are extremely important. Bilateral luxatio erecta is an extremely rare condition and few cases have been reported in the literature.

In this paper, we report a case of traumatic bilateral luxatio erecta that occurred six years earlier, which was given immediate treatment consisting of closed reduction in a surgical environment, provisional immobilization and subsequent referral for physiotherapy treatment.

\section{CASE REPORT}

In September 2004, a 43-year-old man was brought by ambulance from a neighboring municipality to the Emergency Department of the Santa Maria University Hospital with a complaint of bilateral shoulder pain and incapacity to lower his arms.

According to his own report, in unloading sand from a tipper truck, the dropside fell suddenly on his back, causing him to fall to the ground with both arms abducted. He immediately started feel severe pain in the region of his shoulders and was incapable of getting up because he was unable to lower his arms (Figure 1).

On physical examination, he was found to have both shoulders abducted at approximately $110^{\circ}$ and to be incapable of getting out of this position, with his elbows flexed, forearms pronated and hands resting on his head. He presented pain on palpation of the shoulder region and pain when attempts were made to perform passive adduction. Both of the humeral head were palpable in the thoracic wall, close to the ax-

1- Orthopedic and traumatology physician of the Orthopedics and Traumatology Service of the Hospital Universitário de Santa Maria - RS, Brasil.

2- Medical student at the Universidade Federal de Santa Maria - RS, Brazil.

3- Specialist resident physician in orthopedics and traumatology at the Hospital Universitário de Santa Maria - RS, Brasil.

Work carried out at theHospital Universitário de Santa Maria - RS, Brasil.

Correspondence: Rua General Neto, 180, Ap. 1006, Santa Maria, Rio Grande do Sul. 97050-240 E-mail: elemarsr@gmail.com

Received for publication: 10/30/2010, accepted for publication: 12/01/2011

The authors declare that there was no conflict of interest in conducting this work 
illa. Vascular function was not compromised in either extremity, as verified through the presence of radial pulse. However, he presented a deficit in attempting extend the first finger of the right hand, which characterized an injury to the radial nerve in this limb.

Radiographic examination showed interior displacement of the humeral head in relation to the glenoid fossa of both shoulders, and fracturing of the greater tubercle of the right humerus (Figure 2).

The patient was referred to the surgical sector, where closed reduction was performed under anesthesia (fentanyl $250 \mathrm{mg}$ and propofol $200 \mathrm{mg}$ ), by means of the traction-countertraction maneuver on both shoulders. Immediately after this, he was immobilized using a Velpeau sling, to keep the shoulders fully adducted and rotated internally. A control radiographic examination showed that adequate reduction had been achieved in both joints (Figure 3 ).

On the following day, the patient was discharged under instructions to maintain the immobilization for three weeks and then undergo physiotherapy.

He underwent physiotherapy for 12 weeks, during which he partially recovered his range of motion $\left(90^{\circ}\right.$ of abduction in the left shoulder and $100^{\circ}$ in his right shoulder).

He returned to the traumatology outpatient clinic of the university hospital in September 2009, with a complaint of pain when moving his left shoulder and continuing difficulty in extending his first finger on this right hand. Magnetic resonance imaging was performed on the right humeral-scapular joint, which showed unevenness in the anterior appearance of the humeral head, with cortical-subcortical depression

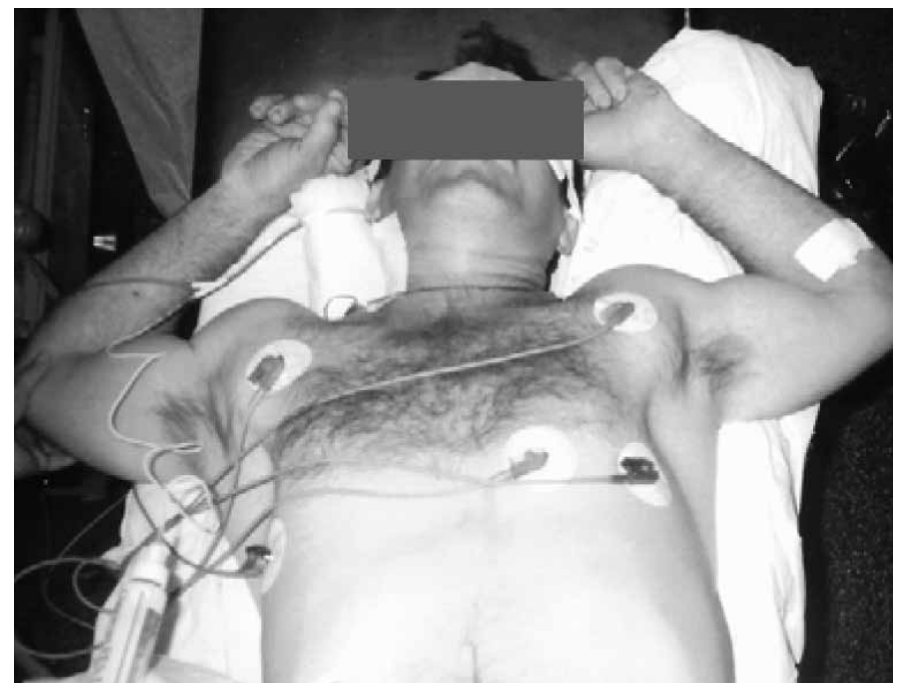

Figure 1 - Patient with inferior dislocation of the shoulders bilaterally.

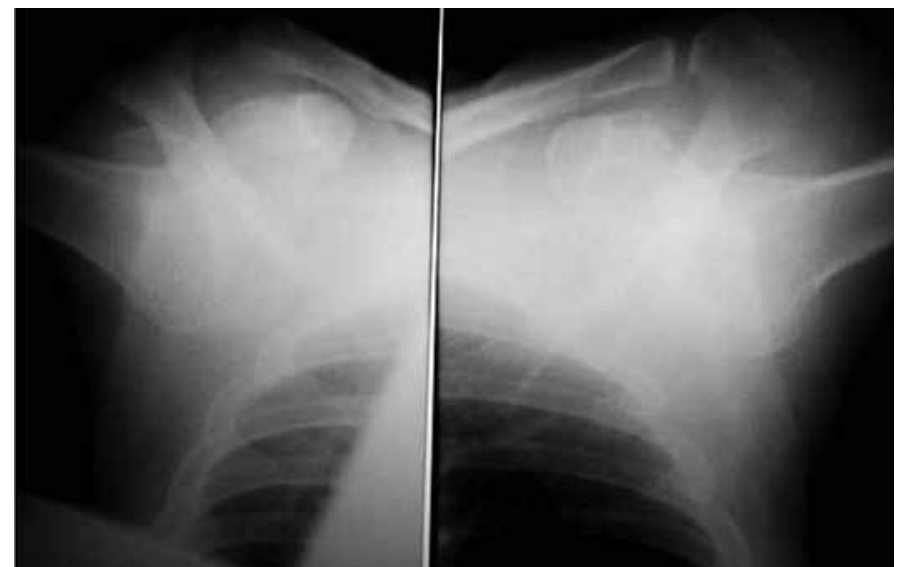

Figure 2 - X-ray of the shoulders in AP view, showing bilateral dislocation.

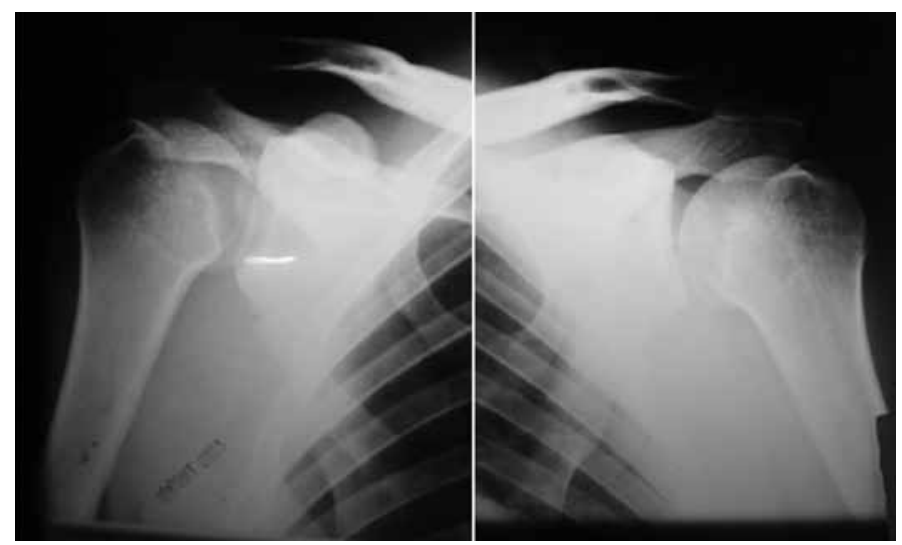

Figure 3 -X-ray in AP view after the reduction.

and signs of tendinosis of the supraspinatus, subscapularis and long head of the biceps brachii.

\section{DISCUSSION}

The shoulder joint has the largest range of motion of all the joints in the body and, because of this characteristic, the incidence of dislocations of this joint is much higher than that of any other joint ${ }^{(1,2)}$.

Inferior dislocation of the glenohumeral joint is an extremely rare entity and represents around $0.5 \%$ of the dislocations of this segment ${ }^{(2,3)}$. The first report of this injury was made by Middeldorpf and Scharm in 1859, while the first report on bilateral occurrence was made by Murard in 1920, apud Musmecci et al ${ }^{(4)}$.

This injury is generally caused by a hyperabduction force that leads the humeral neck to collide with the acromion, thus levering the humeral head inferiorly outwards. The humerus then remains locked, with the head below the glenoid cavity and the diaphysis pointing upwards ${ }^{(5)}$. However, the injury may also, less commonly, be caused by a direct trauma mechanism, by means of an axial load that is directed downwards 
on the arm, with the shoulder completely abducted and the elbow extended ${ }^{(6)}$. As a result of either of these two mechanisms, the lower portion of the joint capsule ruptures and inferior dislocation occurs ${ }^{(7)}$. In the case presented in this report, the trauma mechanism was concordant with the first description, given that the individual in question suffered trauma to the dorsal region that caused a fall to the ground with both arms abducted, thereby causing the dislocation.

The clinical presentation of inferior luxation of the glenohumeral joint is typical, with the arms fixed in an abducted position, elbows flexed, forearms pronated and hands resting on the head. Small passive movements are possible, but are greatly compromised because of the intense pain. The humeral head is also palpable in the region of the axilla ${ }^{(3,7,8,10)}$. The case described here had a presentation exactly the same as these previous descriptions.

Radiographic examinations are necessary for confirming the diagnosis and ruling out possible fractures. The AP and Y views are the ones most used. The AP view shows the axis of the humerus directed superiorly, aligned parallel to the scapular spine. The humeral head is positioned inferiorly to the glenoid cavity, without contact with its rim. The X-ray examination also serves to assess possible associated fractures or concomitant acromioclavicular dislocation ${ }^{(7,11)}$. In the case described here, in addition to the dislocation of both glenohumeral joints, fracturing of the greater tubercle of the right humerus was observed.

Many injuries have been found in association with this injury ${ }^{(11)}$. Fractures or lesions of the rotator cuff have been described in approximately $80 \%$ of the cases; neurological manifestations (most commonly, injury to the axillary nerve) in $60 \%$; and vascular lesions in $3 \%{ }^{(6,11)}$. Neurological deficits resolve rapidly and may either cease soon after the reduction or last for one to two weeks, which suggests that the injury

\section{REFERENCES}

1. Garcia R, Ponsky T, Brody F, Long J. Bilateral luxatio erecta complicated by venous thrombosis. J Trauma. 2006;60(5):1132-4.

2. Laskin RS, Sedlin ED. Luxatio erecta in infancy. Clin Orthop Relat Res. 1971;80:126-9.

3. Karaoglu S, Guney A, Ozturk M, Kekec Z. Bilateral luxatio erecta humeri. Arch Orthop Trauma Surg. 2003;123(6):308-10.

4. Musmeci E, Gaspari D, Sandri A, Regis D, Bartolozzi P. Bilateral luxatio erecta humeri associated with a unilateral brachial plexus and bilateral rotator cuff injuries: a case report. J Orthop Trauma. 2008; 22(7):498-500

5. Rockwood CA, Thomas SC, Matsen FA. Subluxações e luxações da articulação glenohumeral. In: Bucholz RW, Heckman JD, editores. Fraturas em adultos. 5a. ed. São Paulo: Manole; 2006. p. 1003-156

6. Mallon WJ, Bassett FH 3rd, Goldner RD. Luxatio erecta: the inferior glenohumeral dislocation. J Orthop Trauma. 1990;4(1):19-24.

7. Yanturali S, Aksay E, Holliman CJ, Duman O, Ozen YK. Luxatio erecta: clinical presentation and management in the emergency department. J Emerg Med. 2005;29(1):85-9. mechanism is most commonly neuropraxia ${ }^{(8,11,12)}$. The incidence of vascular lesions is low, but it is still greater than in other types of shoulder dislocation ${ }^{(1,6)}$. In the case described here, the patient presented associated lesions consisting of fracturing of the greater tubercle and radial nerve injury, both in the right humerus.

The prognosis for this injury is generally favorable, although significant chronic morbidity may arise, such as adhesive capsulitis or joint instability. Recurrent inferior dislocation is very uncommon ${ }^{(13)}$.

The treatment generally consists of closed reduction of the dislocation, with appropriate muscle relaxation and anesthesia. The reduction technique generally used is traction-countertraction, in which traction is applied to the totally abducted limb while countertraction is applied using a cloth placed superiorly on the ipsilateral shoulder. When the humeral head has been reduced to the glenoid cavity, the limb is totally adducted and is placed in immobilization, which should be maintained for at least two weeks ${ }^{(3,6,8,11,14)}$. IN some cases, closed reduction is not possible, and open reduction is necessary ${ }^{(4)}$. In the present case, the traction-countertraction technique was used successfully for reducing both joints.

\section{CONCLUSION}

Although inferior dislocation of the glenohumeral joint (luxatio erecta) is rare and even more so when it occurs bilaterally, its dramatic presentation and the patient's condition at the time of the assessment made the diagnosis easy. However, the examiner always needs to be alert to the possibility of neurological or vascular lesions, or injuries to the rotator cuff tendons, which would complicate this injury. Rapid appropriate treatment provides excellent results with minimal sequelae.
8. Camarda L, Martorana U, D'Arienzo M. A case of bilateral luxatio erecta. J Orthop Traumatol. 2009;10(2):97-9.

9. Begaz T, Mycyk MB. Luxatio erecta: inferior humeral dislocation. J Emerg Med. 2006;31(3):303-4.

10. Mills LD, Barrows T, Benitez F. Bilateral luxatio erecta. J Emerg Med. 2003;24(1):61-3.

11. Brady WJ, Knuth CJ, Pirrallo RG. Bilateral inferior glenohumeral dislocation: luxatio erecta, an unusual presentation of a rare disorder. J Emerg Med. 1995;13(1):37-42.

12. Tsuchida T, Yang K, Kimura $Y$, Taniwaki M, Ishigaki S, Itoi E. Luxatio erecta of bilateral shoulders. J Shoulder Elbow Surg. 2001;10(6):595-7.

13. Féry A, Sommelet J. [Erect dislocation of the shoulder (luxatio erecta humeri). General review apropos of 10 cases]. Int Orthop. 1987;11(2):95-103.

14. Dahmi FZ, Moujtahid M, El Andaloussi Y, Bekkali Y, Zaouari T, Nechad M, et al. [Luxatio erecta of the shoulder. Report of eight cases]. Chir Main. 2008;27(4):167-70. 